\title{
Evaluation of Microshear Bond Strength of Self- Adhesive Versus Conventional Flowable Resin Composite to Sound and Affected Dentin: An in vitro Study
}

\author{
Dalia M. Abouelmagd*, Hanan K. Abouelseoud** \\ *, **Professors, Restorative Dental Science Department, Faculty of Dentistry, King Abdulaziz University, \\ Jeddah, SA, Cairo University, Egypt. \\ Corresponding Author: Dalia M. Abouelmagd
}

\begin{abstract}
Objectives: This study aimed to compare the microshear bond strength ( $\mu$ SBS) of self-adhesive flowable composite and conventional bonded flowable composite to sound and caries affected dentin. Materials and Methods: In this in vitro study, a total of freshly extracted 40 human molar teeth were used. The occlusal surface was sectioned to expose dentin for $\mu$ SBS test. The teeth were randomly divided into 2 groups according to the type of flowable composite used into two groups $(n=20)$ : group A: self- adhesive flowable composite (Vertise flow), group B: Filtek Z350-XT flowable composite and one-step self-etch adhesive Adper Easy One. A plastic cylindrical mold was used to construct resin composite cylinders $(0.8 \mathrm{~mm}$ diameter $\mathrm{x} 1 \mathrm{~mm}$ length $)$ on the sound and caries affected exposed dentin and filled with flowable composite restorative materials according to manufacturer's instructions. The samples were then immersed in distilled water at $37^{\circ} \mathrm{C}$ for 24 hours, and underwent $\mu$ SBS test at a crosshead speed of $0.5 \mathrm{~mm} / \mathrm{min}$. Data were analyzed using Student's t-test to compare between the two materials as well as to compare between sound and caries affected dentin.

Results: The mean values of $\mu$ SBS of Filtek Z-350XT to sound and caries affected were 26.6 and 26.7 MPa respectively. The mean $\mu$ SBS of Vertise Flow to sound and affected were 13.2 and 17.9 MPa respectively. With sound dentin FiltekZ-350XT showed statistically significant higher $\mu$ SBS than Vertise flow. With caries affected dentin, there was no statistically significant difference between the two materials. There was no statistically significant difference between $\mu$ SBS of sound and caries affected dentin within each material. The significance level was set at $\mathrm{P} \leq 0.05$.

Conclusions: Within the limitations of this study, the conventional flowable composite yielded the highest $\mu$ SBS to sound dentin. There was no statistical significant difference in $\mu$ SBS of self-adhesive and conventional flowable to caries affected dentin.
\end{abstract}

Keywords: Composite Resins; Dentin; microshear

\section{INTRODUCTION}

Tooth-colored restorative materials are increasingly used for dental restorations due to excellent esthetics and the considerable progress in adhesion technology. Vertise flow is the first selfadhering resin composite for direct restorations introduced in the market. Its formulation incorporates the Optibond adhesion technology, eliminating the different bonding steps. Integrating an acidic- adhesive -free composite may lead to the interaction between the material and tooth structures, both chemically and micromechanically ${ }^{(1)}$.

Conventional flowable resin composites do not have adhesive properties, the use of a dental bonding system is 
necessary ${ }^{(2)}$. Self-etch adhesive systems have been gaining in popularity, mainly due to their simplified handling ${ }^{(3-6)}$. While these systems have been shown to have a number of clinical advantages, additional research is still needed to determine the bonding efficiency of self-etch adhesives in different dentin substrates ${ }^{(3,7-9)}$.

Caries-affected dentin is uninfected, partially demineralized and physiologically remineralizable, therefore should be preserved during clinical procedures ${ }^{(10)}$. The changes seen in caries-affected dentin may affect the adhesive properties.

The clinical success of flowable composite depends on the ability of the material to adhere to the dental surface ${ }^{(11)}$; however, little information is available regarding the bond strengths of selfadhering flowable composites to affected dentin.

Therefore, the aim of this study was to compare the $\mu \mathrm{SBS}$, of a self-adhering composite to a conventional flowable composite used with a self-etch adhesive system with different dentin substrates. The following null hypotheses was tested; the simplified flowable composite (Vertise flow) with no additional adhesive system would bond less efficiently to both sound and affected dentin when compared to conventional flowable (Filtek Z350-XT) preceded by self-etch adhesive system.

\section{MATERIALS AND METHODS}

This in vitro study was done on 40 freshly extracted human molar teeth with moderate occlusal caries. The teeth were cleaned, stored in distilled water and used within 2 weeks following extraction.

Enamel and infected dentin of occlusal surfaces of all molars were then ground using a rotary grinding machine under water coolant to produce a flat occlusal surface.

To obtain standard smear layer, 600 grit silicon carbide sand paper was used. The teeth were mounted to the cementoenamel junction in self cure acrylic resin so that the occlusal dentin surface of teeth was situated horizontally.

The ground flat occlusal surfaces were examined for the presence of cariesaffected dentin with 2 methods: 1- Visual and tactile examination: visual examination was done to check dentin color. The texture of dentin was examined tactilely using a sharp explorer. Light to dark brown dentin, firm in texture was considered as caries affected dentin ${ }^{(12)}$.

2- Caries detector dye: ground flat occlusal surfaces were stained using caries detector dye (Kurary Medical Inc., Sakazu, Kurashiki, Okayama, Japan).

According to the manufacturer's recommendations, the caries detector solution was applied on the dentin surface for 10 seconds and then washed. The soft and dark-red stained dentin was considered as caries infected dentin and was removed while the harder pink- stained dentin was considered caries affected and was left. Each flat surface should reveal normal and caries affected dentin without pulp exposure.

The selected stained teeth were divided into 2 groups ( $\mathrm{n}=20)$ according to the flowable composite used. Table 1 shows the materials used in the study. Both types of flowable composite were bonded to both sound and caries- affected dentin in each tooth to eliminate substrate variability between different teeth ${ }^{(12)}$.

After the adhesive application according to manufacturer's instructions (table 1), clear cylindrical plastic tubes, 0.8 $\mathrm{mm}$ internal diameter $1.0 \mathrm{~mm}$ height, were placed on the flat surface of both sound and affected dentin and subjected to light curing. After curing, each tube was filled with flowable resin composite:

Group A: Self- adhesive flowable composite (Vertise Flow).

Group B: Filtek Z350-XT and 1-step selfetch adhesive (Adper Easy One).

Light curing was performed using a LED light curing unit (Blue phase; Ivoclar Vivadent, Schaan, Lichtenstein) with a light intensity of $600 \mathrm{Mw} / \mathrm{cm} 2$ for 20 seconds. 
Dalia M. Abouelmagd et.al. Evaluation of microshear bond strength of self-adhesive versus conventional flowable resin composite to sound and affected dentin: an in vitro study.

The light intensity was checked using a radiometer (Demetron L.E.D Radiometer, CA, USA). After polymerization, plastic molds were removed with a scalpel and the samples checked for voids or cracks. The mounted teeth were immersed in distilled water at $37{ }^{\circ} \mathrm{C}$ for 24 hours.

Microshear bond strength was determined using a universal testing machine (Lloyd LRX-Foreham, UK) at a cross-head speed of $0.5 \mathrm{~mm} / \mathrm{min}$. The data were recorded in MPA using computer software (Nexagen-MT, Lloyd instrument). Data were presented as mean and standard deviation (SD) values. Student's t-test was used to compare between the two materials as well as to compare between sound and caries affected dentin.

The significance level was set at $\mathrm{P} \leq$ 0.05. Statistical analysis was performed with IBM ${ }^{\circledR}$ SPSS $®$ Statistics Version 20 for Windows.

Table 1: Materials used in this study

\begin{tabular}{|c|c|c|c|}
\hline Product name & Manufacturer & Composition & Instructions for use \\
\hline Vertise Flow & $\begin{array}{l}\text { Kerr, Orange, CA, } \\
\text { USA }\end{array}$ & $\begin{array}{l}\text { GPDM adhesive monomer, UDMA, Bis-GMA, Pre- } \\
\text { polymerized filler containing } \\
\text { barium glass filler, nano-sized colloidal silica, nano- } \\
\text { sized } \\
\text { ytterbium fluoride }\end{array}$ & $\begin{array}{l}\text { Brush a thin layer }(<0.5 \mathrm{~mm}) \text { of } \\
\text { Vertise Flow } \\
\text { for } 15-20 \mathrm{~s} \text {, Light cure for } 20 \mathrm{~s} \text {. } \\
\text { Build additional } \\
\text { layers }(2 \mathrm{~mm} \text { or less) then light } \\
\text { cure for } 20 \mathrm{~s}\end{array}$ \\
\hline Adper Easy one & $\begin{array}{l}\text { 3M, ESPE, St Paul, } \\
\text { MN, USA }\end{array}$ & $\begin{array}{l}\text { 2- hydroxyethyl methacryate, Bis-GMA, } \\
\text { Methacrylated } \\
\text { phosphoric esters, 1,6 hexanediol dimethacrylate, } \\
\text { Methacrylate functionalized Polyalkenoic acid } \\
\text { (Vitrebond } \\
\text { Copolymer), Finely dispersed bonded silica filler, } \\
\text { Ethanol, } \\
\text { Water, Initiators based on camphorquinone, } \\
\text { Stabilizers }\end{array}$ & $\begin{array}{l}\text { Apply adhesive to tooth surface } \\
\text { for } 20 \mathrm{~s} \text {. Dry } \\
\text { the adhesive for } 5 \mathrm{~s} \text {. Light cure } \\
\text { for } 10 \mathrm{~s}\end{array}$ \\
\hline $\begin{array}{l}\text { Filtek Z350 XT } \\
\text { flowable }\end{array}$ & $\begin{array}{l}\text { 3M, ESPE, St Paul, } \\
\text { MN, USA }\end{array}$ & $\begin{array}{l}\text { BisGMA, TEGDMA and Procrylat resins, ytterbium } \\
\text { trifluoride } \\
\text { filler, zirconia/silica cluster filler, silica filler }\end{array}$ & $\begin{array}{l}\text { Place the composite into the } \\
\text { cavity }(2 \mathrm{~mm}) \\
\text { Light cure for } 20 \mathrm{~s}\end{array}$ \\
\hline
\end{tabular}

GPDM: glycerol phosphate dimethacrylate; Bis-GMA: bisphenol A glycol dimethacrylate; HEMA: hydroxyethylmethacrylate; TEGDMA: triethylene glycol dimethacrylate; UDMA: urethane dimethacrylate

\section{RESULTS}

Two materials are used in this study. Mean values of $\mu$ SBS for Filtek Z350-XT to sound dentin and affected dentin were $26.6 \pm 1.4$ and $26.7 \pm 3.5 \mathrm{MPa}$ respectively, while that for Vertise Flow were 13.2 \pm 2.7 and $17.9 \pm 0.8$ respectively. Both were not statistically significant at $\mathrm{P} \leq 0.05$. (Table 2)

On the other hand, comparing both materials of the study, mean values of $\mu$ SBS for Filtek Z350-XT and Vertise Flow to sound dentin were $26.6 \pm 1.4$ and $13.2 \pm 2.7$ $\mathrm{MPa}$ respectively. Filtek Z350-XT was statistically significantly higher than Vertise Flow at $\mathrm{P} \leq 0.05$. While mean values of $\mu$ SBS for Filtek Z350-XT and Vertise Flow to affected were $26.7 \pm 3.5$ and $17.9 \pm 0.8$ $\mathrm{MPa}$ respectively, both results were not statistically significantly different at at $\mathrm{P} \leq$ 0.05. (Table 3).

Table (2): Mean, standard deviation (SD) values and results of comparison between microshear bond strength of the two materials

\begin{tabular}{|c|c|c|c|c|c|}
\hline \multirow[t]{2}{*}{ Material Dentin } & \multicolumn{2}{|c|}{ Filtek } & \multicolumn{2}{|c|}{ Vertise } & \multirow[t]{2}{*}{$P$-value } \\
\hline & Mean & SD & Mean & SD & \\
\hline Sound & 26.6 & 1.4 & 13.2 & 2.7 & 0.032* \\
\hline Caries affected & 26.7 & 3.5 & 17.9 & 0.8 & 0.074 \\
\hline
\end{tabular}

Table (3): Mean, standard deviation (SD) values and results of comparison between microshear bond strength of sound and caries affected dentin

\begin{tabular}{|c|c|c|c|c|c|}
\hline \multirow{2}{*}{$\begin{array}{c}\text { Dentin } \\
\text { Material }\end{array}$} & \multicolumn{2}{|c|}{ Sound } & \multicolumn{2}{c|}{ Caries affected } & \multirow{2}{*}{-value } \\
\cline { 2 - 5 } & Mean & SD & Mean & SD & \\
\hline Filtek & 26.6 & 1.4 & 26.7 & 3.5 & $\mathbf{0 . 9 8 5}$ \\
Vertise & 13.2 & 2.7 & 17.9 & 0.8 & $\mathbf{0 . 0 7 1}$ \\
\hline
\end{tabular}




\section{DISCUSSION}

Caries affected dentin is partially demineralized, with no bacteria and with reversible collagen changes $(10,13)$. So, it should be maintained during cavity preparation ${ }^{(14)}$. Provided a wide area of cavity floor after caries removal is caries affected dentin ${ }^{(10,14)}$, study on bonding to caries affected dentin is necessary. Caries affected dentin contains bigger apatite crystallites with lower collagen crosslinkages $(15,16)$, and wider spaces in the inter-tubular dentin.

The deposition of minerals in the dentin tubules of caries affected dentin interfere with full penetration of resin monomers and formation of resin tags ${ }^{(16)}$. Therefore, the hybrid layer of caries affected dentin is thick and poorer in quality (15)

In this study two commercially available flowable composites were tested. Given the numerous clinical applications for which flowable materials are being used, it is important to have adequate comparative information to allow dentists to select the material with the most appropriate properties for any particular use (17). Recently, there has been increased interest in self-adhering flowable composite technology.

In the current study $\mu$ SBS values of Filtek flowable Z350-XT preceded by the use of Adper easy one were higher than the vertise flow for both sound and affected dentin, thus the null hypothesis was accepted. This could be attributed to the use of one step self-adhesive (Adper easy one) before its placement. Smear layer removal or modification is essential for the formation of a high quality hybrid layer and it provides optimal adhesion to dentin ${ }^{(18)}$. For the selfetch adhesives, smear layer modification is dependent on the $\mathrm{pH}$ of the primer used ${ }^{(19}$, 20). Adper Easy One has a pH of 3.5 is regarded as a mild self-etch adhesive. Although Vertise ${ }^{\mathrm{TM}}$ Flow had a more acidic $\mathrm{pH}$; the lowest bond strength values were obtained with this material. According to the results of our study, there is no direct correlation between acidic $\mathrm{pH}$ of the material and the bond strength, this result is in accordance with Almaz et al, $2016^{(21)}$.

The low $\mu$ SBS of vertise flow to sound dentin could be due to the high filler content which may increase the viscosity and reduce the wetting of dentin surface, decreasing the monomer penetration and lowering the bond strength ${ }^{(22-24)}$.

Also the lower $\mu$ SBS of Vertise Flow may be attributed to the incorporation of a bonding agent into the resin material, causing incomplete infiltration of adhesive into demineralized dentin, ineffective sealing of dentin tubules, and degradation of exposed collagen and the resin material ${ }^{(25)}$.

Filtek Z350-XT should be preceded by adhesive application, "Mild" self-etching appears most promising, especially with regard to bond stability ${ }^{(26)}$. In the light of bonding durability, mild self-etch adhesives have unique property that all hydroxyapatite are not removed from the interaction zone, and much calcium is available for additional chemical interaction with specific adhesive monomers. So, the bonds are stable, even in the aqueous environment and the mechanism is supposed to prolong the clinical lifetime of the restorations ${ }^{(27)}$ Also, the preservation of hydroxyapatite around the collagen in mild self-etch adhesives may protect the collagen against hydrolysis and thus prevents the early degradation of the bonds.

Furthermore, Adper Easy one contains ethanol as a cosolvent. Ethanol is a polar solvent that will form hydrogen bonds with its solutes. Ethanol removes water from these spaces, thus increasing the interfibrillar spaces and allowing more resin infiltration ${ }^{(28)}$.

On the other hand, the $\mu$ SBS of Filtek Z 350-XT to affected dentin although higher than to Vertise flow but was not statistically different and there was no statistical significant difference between bonding to sound and affected dentin for both tested materials which could be due to the presence of an adhesive monomer called glycerol phosphate dimethacrylate "GPDM" 
in self-adhering flowable composite "Vertise flow". GPDM is a functional monomer that is responsible for etching the tooth structure and also for chemically bonding to the calcium ions within the tooth structure. On the other hand, it has two methacrylate functional groups for copolymerization with other methacrylate monomers to provide increased cross linking density and enhanced mechanical strength for the polymerized adhesive. The resin also contains hydroxyethyl methacrylate, which is used to provide wetting and resin penetration in dentin. Eliminating the need for a separate adhesive application holds great potential for saving chair time and minimizing handling errors $(29,30,31)$.

In addition, this could be attributed to the application of self-adhering flowable composite by brushing a thin layer $(<0.5$ $\mathrm{mm}$ ) of Vertise Flow for 15-20 s to form the hybrid layer which increased the $\mu$ SBS of self-adhering flowable composite to dentin surface. This was in accordance with Chan et al ${ }^{(32)}$ who stated that bond strength of self-etch adhesive on dentin surface significantly increased after brushing selfadhesive flowable on thick smear layer.

\section{CONCLUSIONS}

Under the limitations of this study it can be concluded that:

- The bond strength of conventional flowable to sound dentin was higher than self-adhesive flowable.

- The bond strength of self- adhesive flowable to caries affected dentin was not statistically different from bonding of conventional flowable.

Acknowledgement: None

Conflict of Interest: None

Source of Funding: None

Ethical Approval: Approved

\section{REFERENCES}

1. Fu J, Kakuda S, Pan F, Hoshika S, Ting S, Fukuoka A, Bao Y, Ikeda T, Nakaoki Y, Selimovic D, Sano H. Bonding performance of a newly developed stepless all-in-one system on dentin. Dental materials journal. 2013; 32(2):203-11. https://doi.org/10.4012/dmj.2012-204 PMid: 23538754

2. Tay FR, Pashley DH. Have dentin adhesives become too hydrophilic? J Can Dent Assoc. 2003; 69(11): 726-731.

3. Cardoso MV, de Almeida Neves A, Mine A, et al. Current aspects on bonding effectiveness and stability in adhesive dentistry. Aust Dent J. 2011; 6 (Suppl 1): 31-44.

4. Fujita K, Ma S, Aida M, et al. Effect of reacted acidic monomer with calcium on bonding performance. J Dent Res. 2011; 90(5): 607-612.

5. Teixeira CS, Chain MC. Evaluation of shear bond strength between self-etching adhesive systems and dentin and analysis of the resin-dentin interface. Gen Dent 2010; 58:e52-61.

6. Ermis RB, Van Landuyt KL, Cardoso MV, De Munck J, Van Meerbeek B, Peumans M. Clinical effectiveness of a one step self-etch adhesive in non-carious cervical lesions at 2 years. Clin Oral Investig. 2012; 16(3): 889-897.

7. Peumans M, Kanumilli P, De Munck J, Van Landuyt K, Lambrechts $P$, Van Meerbeek B. Clinical effectiveness of contemporary adhesives: a systematic review of current clinical trials. Dent Mater. 2005; 21(9): 864-881.

8. Kubo S, Kawasaki K, Yokota H, Hayashi Y. Five-year clinical evaluation of two adhesive systems in non-carious cervical lesions. J Dent. 2006; 34(2): 97-105.

9. Walter R, Swift EJ Jr, Nagaoka H, et al. Two-year bond strengths of "all-in-one" adhesives to dentine. J Dent. 2012; 40(7): 549-555.

10. Nakajima $\mathrm{M}, \quad$ Kunawarote $\mathrm{S}$, Prasansuttiporn T, Tagami J. Bonding to caries-affected dentin. Japanese Dental Science Review (2011) 47, 102-114.

11. Vichi A, Goracci C, Ferrari M. Clinical study of the self-adhering flowable 
Dalia M. Abouelmagd et.al. Evaluation of microshear bond strength of self-adhesive versus conventional flowable resin composite to sound and affected dentin: an in vitro study.

composite resin Vertise Flow in Class I restorations: six-month follow-up. International Dentistry SA. 2010; 12: 1423.

12. Mobarak EH, El-Badrawy WH. Microshear bond strength of self-etching adhesives to caries-affected dentin identified using the dye permeability test. J Adhes Dent 2012; 14(3): 245-50.

13. Erhardt MCG, Osorio R, Toledano M. Dentin treatment with MMPs inhibitors does not alter bond strengths to cariesaffected dentin. J Dent 2008; 36:106873.

14. Scholtanus, J. D.; Purwanta, Kenny; Dogan, Nilgun; Kleverlaan, Cees J.; Felizer, Albert J. Microtensile Bond Strength of Three Simplified Adhesive Systems to Caries-affected Dentin. Journal of Adhesive Dentistry. 2010, Vol. 12 Issue 4, p273-278.

15. Wei S, Sadr A, Shimada Y, Tagami J. Effect of caries-affected dentin hardness on the shear bond strength of current adhesives. J Adhes Dent 2008; 10:43140.

16. Tekce N, Tuncer S, Demirci M.The bonding effect of adhesive systems and bulk-fill composites to sound and cariesaffected dentine. Journal of Adhesion Science and Technology. 2015: 30(2):115.

17. Attar, N, Tam, L.E, McComb, D. Flow, strength, stiffness and radiopacity of flowable resin composites. J Can Dent Assoc. 2003; 69(8): 516-521.

18. Van Meerbeek B, De Munck J, Yoshida $\mathrm{Y}$, Inoue $\mathrm{S}$, Vargas $\mathrm{M}$, Vijay $\mathrm{P}$, et al. Buonocore memorial lecture. Adhesion to enamel and dentin: Current status and future challenges. Oper Dent 2003; 28: 215-35.

19. Ermis RB, De Munck J, Cardoso MV, Coutinho E, Van Landuyt KL,Poitevin A, et al. Bond strength of self-etch adhesives to dentin prepared with three different diamond burs. Dent Mater 2008; 24:97885.

20. Nakabayashi N, Pashley DH. Hybridization of Dental Hard Tissues. Japan: Quintessence Publishing Co.; 1998. p. 37-56.
21. Almaz ME, Oba AA, Sönmez IS , Sönmez D . Comparison of shear bond strength of self adhering flowable composite with different flowable composites to dentin. European Journal of General Dentistry 2016; 5: 6-10.

22. Miyazaki M, Ando S, Hinoura K, Onose $\mathrm{H}$, Moore BK. Influence of filler addition to bonding agents on shear bond strength to bovine dentin. Dent Mater 1995; 11:234-8.

23. Bektas OO, Eren D, Akin EG, Akin H. Evaluation of a self-adhering flowable composite in terms of micro-shear bond strength and microleakage. Acta Odontol Scand 2013; 71:541-6. 2

24. Tuloglu N, Sen Tunc E, Ozer S, Bayrak S. Shear bond strength of self adhering flowable composite on dentin with and without application of an adhesive system. J Appl Biomater Funct Mater 2014; 12:97 101.

25. Viotti, R.G. , Kasaz, A. , Pena, C.E. , Alexandre, R.S. , Arrais, C.A. , Reis, A.F. Microtensile bond strength of new selfadhesive luting agents and conventional multistep systems. J Prosthet Dent. 2009; 102(5): 306-312. Google Scholar | Crossref | Medline | ISI

26. Van Meerbeek B, De Munck J, Yoshida $\mathrm{Y}$, Inoue S, Vargas M, Vijay $\mathrm{P}$, et al. Adhesion to enamel and dentin: Current status and future challenges. Oper Dent. 2003; 28:215-35. [PubMed] [Google Scholar]

27. Chersoni S, Suppa P, Grandini S, Goracci C, Monticelli F, Yiu C, et al. In vivo and vitro Permeability of One-step Self-etch Adhesives. J Dent Res. 2004;83:459-64. [PubMed] [Google Scholar]

28. Nishitani Y, Yoshima M, Donnelly AM, Agee KA, Sword J, Tay FR, et al. Effect of resin hydrophilicity on dentin bond strength. J Dent Res. 2009; 88:146-51. [Google Scholar]

29. Vichi A, Margvelashvili M, Goracci C, Papacchini F, Ferrari M. Bonding and sealing ability of a new self adhering flowable composite resin in class I restorations. Clin Oral Investig 2013; 17:1497506. 
Dalia M. Abouelmagd et.al. Evaluation of microshear bond strength of self-adhesive versus conventional flowable resin composite to sound and affected dentin: an in vitro study.

30. Garcia RN, Silva CS, Silva GG, Mocellin G, Ozelame J, Fracasso L, Ozelame MB, do Nascimento RF, Gomes AC. Bonding performance of a self-adhering flowable composite to indirect restorative materials. RSBO Revista Sul-Brasileira de Odontologia. 2014; 11(1):6-12.

31. Poorzandpoush K, M Shahrabi M, Heidari A, Hosseinipour ZS. Shear Bond Strength of Self-Adhesive Flowable Composite, Conventional Flowable Composite and Resin-Modified Glass Ionomer Cement to Primary Dentin. Front Dent. 2019; 16 (1):62-68. doi: 10.18502/fid.v16i1.1111
32. Chan K, Tay F, King N, Imazato S, Pashley D. Bonding of mild self-etching primers/adhesives to dentin with thick smear layers. Am J Sent 2003; 16(5): $340-6$.

How to cite this article: Abouelmagd DM, Abouelseoud HK. Evaluation of microshear bond strength of self-adhesive versus conventional flowable resin composite to sound and affected dentin: an in vitro study. Int J Health Sci Res. 2021; 11(4): 306-312. DOI: https://doi.org/10.52403/ijhsr.20210436 